\title{
EX SITU PROPAGATION OF PHILIPPINE RAFFLESIA IN THE UNITED STATES: CHALLENGES AND PROSPECTS
}

\author{
Jeanmaire Molina ${ }^{1}$, William McLaughlin ${ }^{2}$, Kyle Wallick ${ }^{3}$, Ronniel Pedales ${ }^{4}$, Viviane Marcella \\ Marius ${ }^{5}$, Danilo N. Tandang ${ }^{6}$, Amor Damatac II ${ }^{7}$ Nicole Stuhr $^{8}$, Susan K. Pell ${ }^{9}$, Theresa \\ Mundita Lim ${ }^{10}$, Ari Novy ${ }^{11}$
}

\begin{abstract}
The large-flowered parasitic genus Rafflesia R.Br. (Rafflesiaceae) has long fascinated naturalists and scientists and is an iconic symbol for plant conservation. Techniques to effectively propagate members of the genus outside of their natural habitat are sparse, and grafting infected Tetrastigma K.Schum.(Vitaceae) host plants has previously been reported as a successful strategy for ex situ conservation of Rafflesia. Here we report our attempts in the United States to propagate host cuttings infected with Rafflesia speciosa Barcelona \& Fernando and $R$. lagascae Blanco collected from the Philippines, as well as uninfected host material. We also describe efforts to germinate $R$. speciosa seeds in vitro using various plant growth regulators (PGRs). After rooting, infected host cuttings survived for a maximum of 11 months, but did not produce shoots. However, an uninfected cutting of T. cf. magnum grafted onto an established Malaysian species of Tetrastigma in June 2017 has succeeded in the commencement of new growth. Three propagules of a second potential host, T. harmandii Planch., have also been vigorously growing at the United States Botanic Garden since June 2017. However, Rafflesia seeds did not germinate with the application of PGRs, even though the seeds were viable according to tetrazolium (TZ) testing. These ex situ propagation attempts have revealed challenges in propagating these species outside of their native ranges, but our incremental success in rooting infected Tetrastigma, as well as grafting interspecific Tetrastigma species, bodes well for further advances. With Philippine host species, $T$. harmandii and $T$. cf.
\end{abstract}

1. Jeanmaire Molina is an Assistant Professor at Long Island University-Brooklyn and the corresponding author for this paper. Address: Long Island University-Brooklyn, 1 University Plaza, Brooklyn, NY 11201, USA.

Email: jeanmaire.molina@liu.edu

2. William McLaughlin is a Plant Curator at the United States Botanic Garden.

Address: United States Botanic Garden, 245 First Street, SW, Washington, DC 20515, USA.

3. Kyle Wallick is a Botanist at the United States Botanic Garden

Address: as above.

4. Ronniel Pedales is a University Research Associate at the University of the Philippines.

Address: Institute of Biology, College of Science, University of the Philippines, Diliman, Quezon City 1101, Philippines.

5. Viviane Marcella Marius is a local entrepreneur.

Address: Vivian Rafflesia Garden, Poring Springs, Sabah, Malaysia and Universiti Malaysia Sabah, Jalan UMS, 88400, Kota Kinabalu, Sabah, Malaysia.

6. Danilo N. Tandang is a Museum Researcher at the National Museum of the Philippines.

Address: Botany and National Herbarium Division, National Museum of the Philippines, P. Burgos Street, Manila,

Philippines.

7. Amor Damatac II is a University Research Associate at the University of the Philippines.

Address: Institute of Biology, College of Science, University of the Philippines, Diliman, Quezon City 1101, Philippines.

8. Nicole Stuhr is a PhD student at the University of Southern California.

Address: Dornslife College of Arts \& Sciences, 3551 Trousdale Pkwy, Los Angeles, CA 90007, USA.

9. Susan K. Pell is Deputy Executive Director of the United States Botanic Garden.

Address: United States Botanic Garden, 245 First Street, SW, Washington, DC 20515, USA.

10. Theresa Mundita Lim is Director of DENR - Biodiversity Management Bureau (BMB).

Address: DENR Compound, Visayas Avenue, Quezon City, Philippines.

11. Ari Novy is Chief Scientist at the Leichtag Foundation.

Address: Leichtag Foundation, 441 Saxony Rd, Encinitas, CA, USA. 
magnum in cultivation, we can begin using these specimens for future experimentation involving grafting of infected material and Rafflesia seed inoculation trials. Furthermore, we describe new avenues of propagation techniques for Rafflesia as practised by Marius Gabin, one of the owners of the Vivian Rafflesia garden, which contains a natural Rafflesia forest habitat at Poring Springs, Sabah, Malaysia. Gabin openly shared his successes in artificially inoculating Rafflesia seeds into a mature Tetrastigma vine. Gabin's willingness to share his experience highlights the importance of collaborating with practitioners who have developed local knowledge of Rafflesia horticulture and conservation.

\section{INTRODUCTION}

Rafflesia $\mathrm{R}$. Br. is a curious genus of parasitic plants unique to the tropics of Southeast Asia. It produces the world's largest flowers smelling of rotting flesh to lure flies as pollinators. Along with the famous Amorphophallus titanum (Becc.) Becc., members of the unrelated Rafflesia are commonly known as corpse flowers due to their putrid stench. Rafflesia species are obligate parasites, with no stems, roots or leaves. The visible portion of Rafflesia plants consists of a massive flower that can grow up to $1 \mathrm{~m}$ in diameter, as it feeds off and emerges from its host, members of the tropical grape vine genus Tetrastigma (Nais, 2001; Davis et al., 2007). This obligate parasitic relationship afforded Rafflesia to completely lose its plastid genome (Molina et al., 2014), an evolutionary feat unprecedented even in other holoparasites (Barbrook et al., 2006).

Rafflesia belongs to the family Rafflesiaceae (order Malpighiales) along with Sapria Griff. and Rhizanthes Dumort., which are also holoparasites of Tetrastigma, making members of the family fully dependent on this genus for all their nutritional needs. There are at least 30 Rafflesia species, with more than a third of the species endemic to the islands of the Philippines (Barcelona et al., 2009; Pelser et al., 2016). The species' restricted distributions within dwindling forest habitats make several species vulnerable or endangered (Nais, 2001; Barcelona et al., 2009). Recent population genetic analyses have shown that, in spite of small isolated distributions, Rafflesia populations, at least for $R$. lagascae, do not show pronounced inbreeding and may be naturally rare (Pelser et $a l$., in press). The exoticism of these giant malodorous Rafflesia blooms has made them a spectacle to tourists and a charismatic icon of plant conservation.

However, in spite of its iconic status, very few reports exist on how to propagate Rafflesia ex situ (Mursidawati et al., 2015; Wicaksono et al., 2016). This is partly due to a lack of understanding of its complete life cycle, in particular its seed dispersal and germination, as well as insufficient knowledge of the broader concept of the cultivation of holoparasitic plants. Flower buds have high mortality (>90\%) and take 9-16 months to develop prior to anthesis. Flowers are typically unisexual, with more males than females (7:1) (Nais, 2001) but a few species produce bisexual flowers (Balete et al., 2010). Recently, microsatellite (SSR) assay of $R$. lagascae samples revealed genotypically identical male and female flowers emerging from the same host, raising the possibility that at least some species within the genus may be monoecious (Pelser et al., in press). In general, anthesis lasts c. four to eight days. Carrion flies facilitate pollination, attracted 


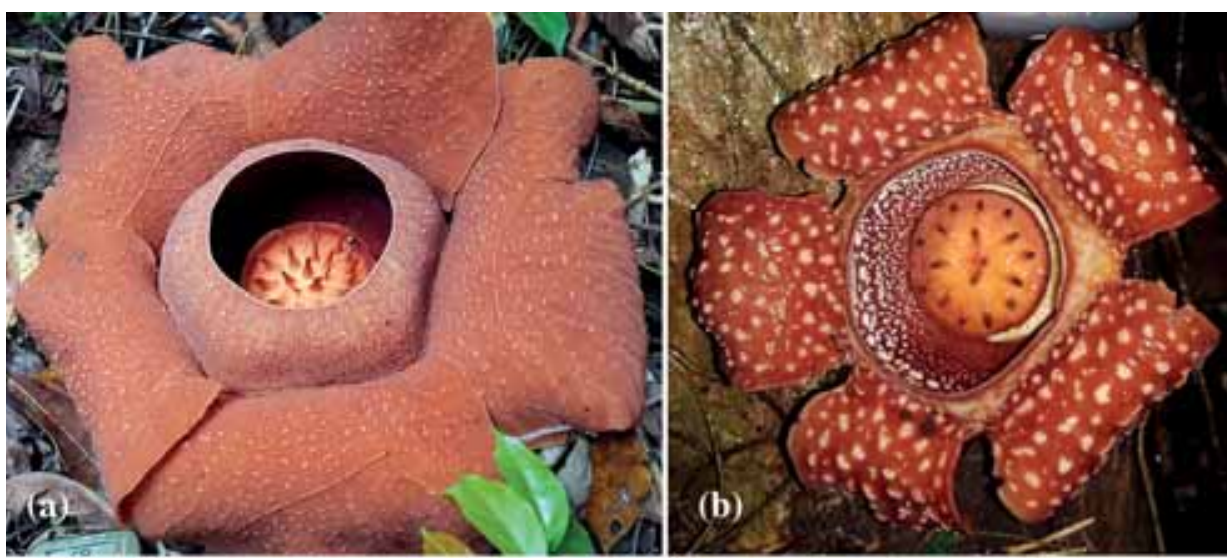

Fig. 1 (a) Open flower of Rafflesia speciosa from Antique, Iloilo (diameter c. $45 \mathrm{~cm}$ ). (b) Open flower of Rafflesia lagascae from San Lorenzo Ruiz, Camarines Norte (diameter c. 20cm). Photo: Jeanmaire Molina.

to the fetid odour of the flower. Fruits mature in six to eight months, each containing more than 200,000 seeds. Small mammals, such as shrews, have been observed to gnaw on the hard covering of the fruits, and are believed to facilitate dispersal (Nais, 2001). Recently, seeds have also been observed to be transported by ants (Pelser et al., 2013). How the seeds enter, germinate and infect the host vine remains a mystery (Nikolov et al., 2014), but multiple infections by more than one Rafflesia plant are possible (Pelser et $a l$., in press). It can take up to four years before flowers emerge from the host after seed germination and host inoculation (Nais, 2001; Wicaksono et al., 2016). Ultrastructural studies of an infected Tetrastigma have shown that the giant-flowered Rafflesia ironically produces the smallest endophytes, as minute proembryos interspersed within the vascular tissue of its host (Nikolov et al., 2014).

Attempts to propagate Rafflesia have met many hurdles (Nais, 2001; Wicaksono et al., 2016). Successful artificial inoculation of the host with Rafflesia seeds was reported in 1857-1924 when flowers emerged from the inoculated vines in Bogor Botanic Garden and the Fern-Bromeliad Garden (Meijer, 1997). This success was not repeated until Nais et al. (2001; 2015), who claimed to have successfully inoculated seeds into the host vine, resulting in an open flower in February 2000 that was visited by over 500 tourists during its one-week anthesis. This suggests the enormous tourism potential for Rafflesia if it can be cultivated in botanic gardens. However, Nais' methods of cultivation are not published and are currently being patented (Wicaksono et al., 2016). There exists only a single published report of grafting Rafflesia-infected host cuttings to a non-infected host vine resulting in multiple blooms from 2004 to 2010 (Mursidawati et al., 2015).

Here, we report attempts to propagate Philippine Rafflesia spp. in an American botanical garden from infected host cuttings grafted onto established, uninfected Tetrastigma plants belonging to a different species. We also report initial results of our efforts to study germination of Rafflesia seeds in vitro using various plant-growth 
regulators known to induce germination in different angiosperm species (Corbineau et al., 2007; Finkelstein, 2010; Flematti et al., 2015; Kępczyński \& Białecka, 1994; Li et al., 2005; Miransari \& Smith, 2014; Pouvreau et al., 2013; Sarath et al., 2006; Sawan et al., 2000; Steber \& McCourt, 2001; Yoneyama et al., 2010). Finally, we discuss a technique to successfully inoculate the host vine with Rafflesia seeds, pioneered by Marius Gabin and daughter, Viviane, owners of the Vivian Rafflesia Garden at Poring Springs, Sabah, Malaysia. Rafflesia gardens are promoted by the Malaysian government. Local growers derive income via Rafflesia gardens from tourists, resulting in sustainable ecotourism $(\mathrm{Ng}, 2012)$. We report these findings to inform future efforts in propagating Rafflesia for ex situ conservation, especially in the Philippines, home to the highest Rafflesia diversity. In addition, we hope this successful example of creating an inclusive indigenous and international partnership for the conservation of this iconic genus will help bolster the case for expending the considerable efforts required to not only develop the technical skills necessary to propagate biologically complicated species, but to navigate the increasingly complex legal frameworks for lawful collection, export and import of living plants.

\section{FIELD COLLECTION AND CARRIAGE OF PHILIPPINE RAFFLESIA AND TETRASTIGMA}

The Philippines is home to 13 species of Rafflesia, all endemic. Rafflesia is protected in the Philippines and collection is prohibited without appropriate permits and consent from concerned local communities. Gratuitous permits no. 242 and 257 were issued by the Biodiversity Management Bureau (BMB) of the Philippines to the author. Field studies were conducted in the Philippines in 2015, 2016 and 2017 at two different sites to collect Rafflesia spp. and their respective hosts. A total of ten underground cuttings of Tetrastigma harmandii and T. cf. magnum (sensu Pelser et al., 2016) infected with Rafflesia speciosa (RST; flower in Fig. 1a) were collected from Miag-ao, Iloilo (Panay Island), as well as five uninfected stem cuttings and three rooted T. harmandii juveniles. About 20,000 seeds (one in ten of the fruit) of $R$. speciosa were also collected. From San Lorenzo Ruiz, Camarines Norte (Luzon Island), a total of 15 aerial stem cuttings of Tetrastigma loheri infected with Rafflesia lagascae (RLT; Fig. 1b) were collected, in addition to six uninfected host cuttings. All cuttings ranged from 13 to $62 \mathrm{~cm}$ long. Infected cuttings have intact Rafflesia buds attached. The orientation of the cuttings was noted (i.e. direction of shoot apex vs root apex), but this is often difficult due to the gnarly habit of the host vine which folds upon itself. Tetrastigma leaves arise on high and inaccessible parts of the vine, while Rafflesia emerges on basal parts lacking leaves, i.e. from shallow roots in RST and mature aerial lower stems in RLT (Fig. 2). Taxonomic identification of the host is only possible when low-hanging branches with foliage are present. Collected cuttings were rinsed of soil and wrapped gently in newspapers. Soil testing was performed at all sites using LaMotte Garden Kit (cat\# 5679-01). Soil pH was generally neutral, measuring 6 or 7 in the two sites. Low amounts of phosphorus, 
nitrogen and potassium (potash) were measured. Specimens were then shipped to the United States Botanic Garden (USBG), after securing the necessary permits, via airfreight in 2015 and 2016, and mostly hand-carried in a sealed box (with carbon packets to absorb ethylene) by William McLaughlin in 2017 to test whether hand-carry will allow specimens to fare better. Specimens arrived at USBG three to seven days later, depending on the process of inspections by border officials. At USBG, collected root/ stem cuttings were sectioned to produce multiple smaller cuttings.

\section{SEED VIABILITY TESTING AND GERMINATION ASSAYS}

The tetrazolium (TZ) test was conducted on 20 Rafflesia speciosa seeds to determine viability (Verma \& Majee, 2013). When this test showed that the seeds were viable, c. 800-1,000 R. speciosa seeds underwent conditioning. In this process, seeds were incubated in $50 \% 1 \mathrm{M}$ HEPES buffer (Sigma cat. H0887) at $30^{\circ} \mathrm{C}$ for either seven or thirty days. Seed conditioning may increase seed coat permeability and change levels of endogenous germination promoters/inhibitors that prepare the seed for germination (Kroshel, 2001). Though it is unknown if conditioning is necessary for Rafflesia, holoparasites in Orobanchaceae do require conditioning before they can respond to germination stimulants. Different holoparasitic species require conditioning temperatures of $18-30^{\circ} \mathrm{C}$ for six weeks in moist environments. After conditioning, various plant growth regulators (PGRs, including gibberellins GA3 and GA4+7, karrikin/KAR1, synthetic strigol GR24, kinetin, sodium nitroprusside/SNP, ethylene and brassinolide/BRA; see Appendix) were applied to conditioned Rafflesia and non-conditioned Rafflesia seeds in three relative concentrations (diluted in 50\% 1M HEPES buffer with $0.2-0.5 \%$ commercial biocide): low, medium (i.e. standard concentration known to induce germination) and high, with exact concentrations of PGR determined from references and product literature (Sigma Aldrich and Olchemim, Czech Republic; see Appendix). Low and high concentrations were multiplied 100-1,000 times lower or higher compared to medium (standard) concentrations. The $\mathrm{pH}$ was adjusted to 6-7 based on the results of soil testing in the field. Wildflower (WF) seeds were also subjected to the same treatments to serve as positive control. Seeds were incubated in germination hoods for up to six weeks at $30^{\circ} \mathrm{C}$ in ambient light. Every three days, seeds were checked for protrusion of the radicle using a stereomicroscope (AmScope SE306-AZ-E2). PGRs were replenished every three days.

PROPAGATION OF CUTTINGS AT USBG

\section{Rafflesia speciosa host cuttings (RST)}

The first set of RST cuttings collected in June 2015 (Fig. 3) were placed on long-fibre, live sphagnum moss upon arrival at USBG. Some were eventually cut, producing a total of nine cuttings. Biological fungicide (commercial proprietary mix of two Trichoderma spp.) was applied prophylactically. White root initials were observed on most cuttings 
Fig. 2 Habit of collected Rafflesia spp. (a) Rafflesia lagascae bud and flowers (c. $20 \mathrm{~cm}$ ) on mature aerial Tetrastigma stems. (b) Rafflesia speciosa bud (c. $5 \mathrm{~cm}$ ) on a shallow-buried Tetrastigma root. Photos: Jeanmaire Molina.
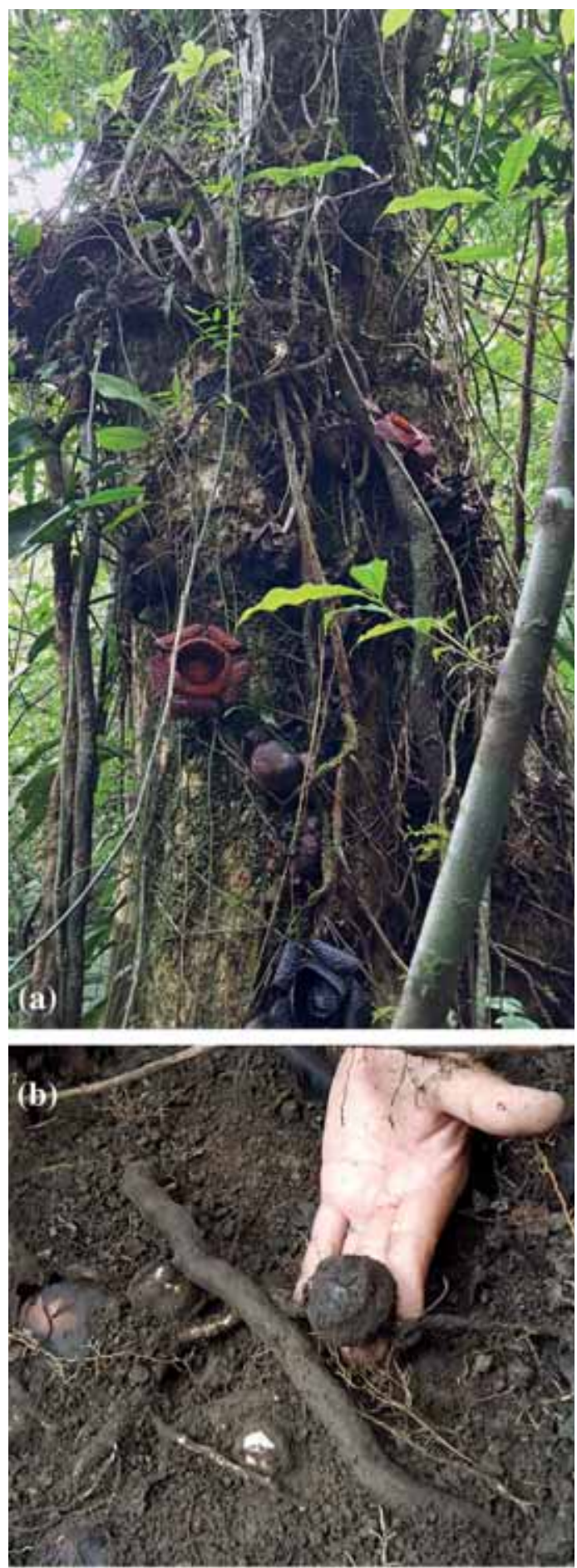


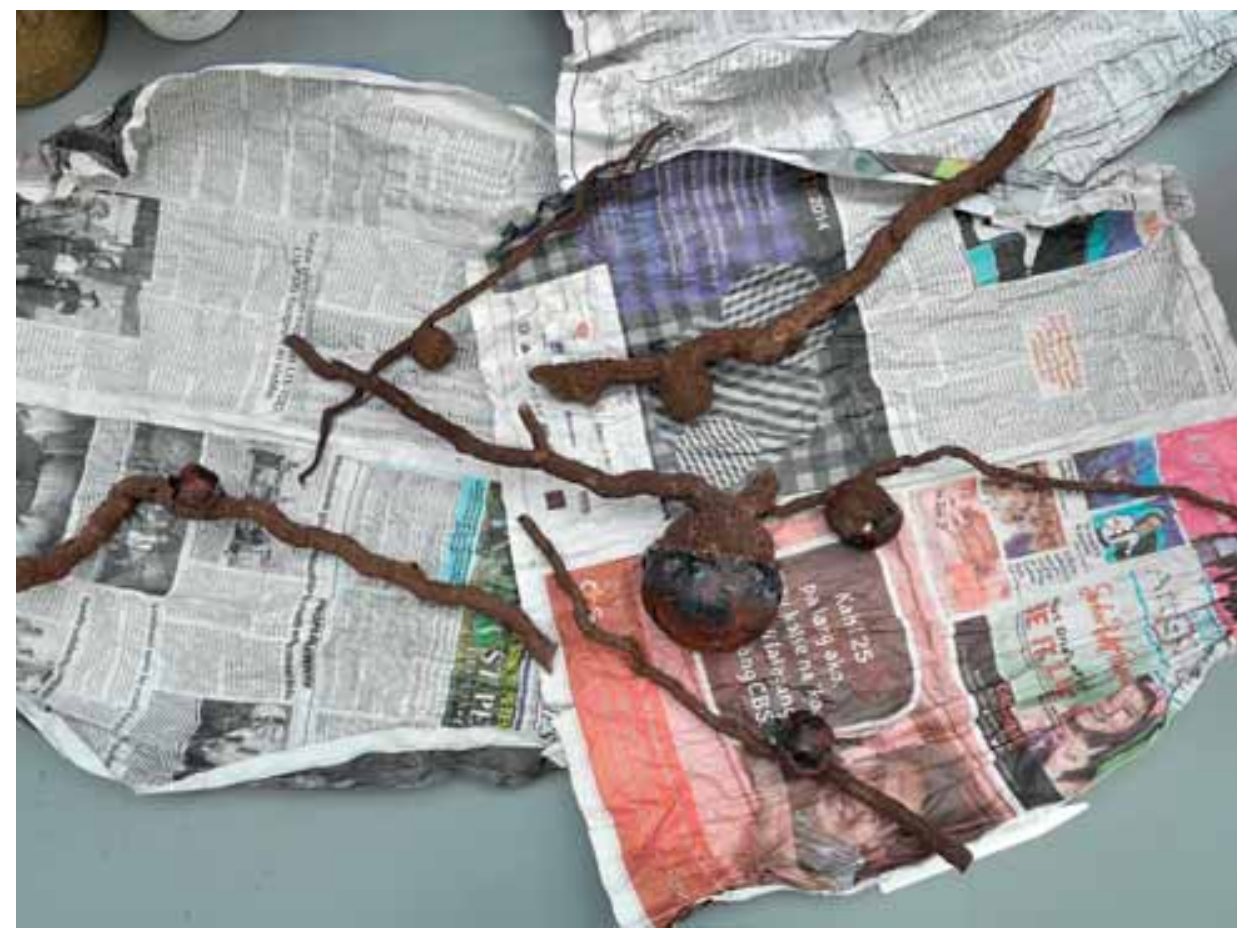

Fig. 3 Arrival of Rafflesia speciosa-infected Tetrastigma (RST) cuttings at USBG in June 2015. Photo: USBG.

after five days, even before application of rooting hormone (indole 3-butyric acid). Dinotefuran (20\% granular at $1.5 \mathrm{tsp} / \mathrm{gal})$ was applied for noted fungus gnats. In one month, several roots were noticed on RST (Fig. 4), but the floral buds were decaying and were excised. Commercial fertiliser was then applied (50 ppm nitrogen), and cuttings were transplanted in commercial potting mix, lightly watered, with bottom heat applied. However, by May 2016, 11 months after arrival, all cuttings had expired. Similarly, RST cuttings collected in August 2016 did not ultimately survive, as they had suffered desiccation during transit. Though some cuttings at first showed root initials after treatment with rooting hormone and $500 \mathrm{ppm}$ gibberellic acid (GA3), they eventually expired within two months.

Most recently, in June 2017, two cuttings from infected Tetrastigma roots and six uninfected Tetrastigma pieces, including three T. harmandii juveniles with root systems, were taken to USBG by William McLaughlin. Two of the juvenile plants have successfully rooted (Fig. 5, background) into sterile soilless potting media and are growing vigorously as of August 2017. Though the third did not ultimately grow, the juvenile plants from the forest have propagated with a high degree of success and these methods should be used where possible. Host cuttings were sectioned to produce multiple $6-12 \mathrm{~cm}$ smaller cuttings, each dipped in rooting hormone and stuck in a 
Fig. 5 Philippine Tetrastigma harmandii plants collected in May 2017 growing at USBG. Foreground plant was an uninfected cutting that has successfully rooted and is growing robustly. The two background plants were collected as juveniles and have been growing vigorously since. Photo: USBG.

Fig. 6 Philippine Tetrastigma cf. magnum collected in May 2017 growing at USBG. The uninfected cutting was grafted onto a mature Malaysian T. rafflesiae and is commencing growth with a terminal bud producing a leaf. Photo: USBG.
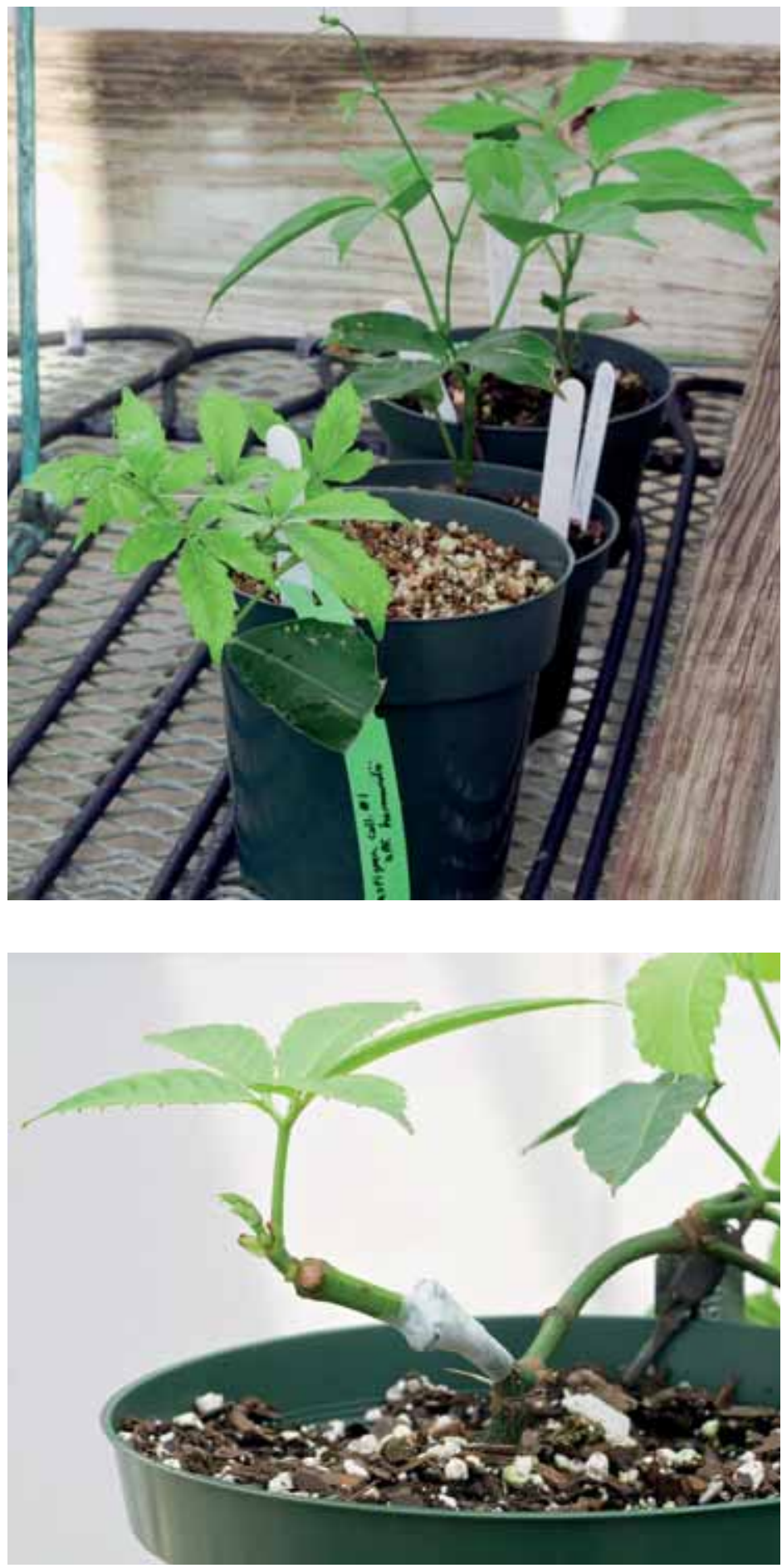
flat of $40 \%$ perlite $/ 40 \%$ vermiculite/20\% sphagnum peat moss. However, most of the cuttings contracted bacterial soft rot infection (Erwinia sp.), including the Rafflesiainfected root pieces, and subsequent drenches with a bactericide were only partially effective. Erwinia may have been present in the irrigation system and in untreated water, and, in future, collected material will be treated with antimicrobials on the day of collection, followed with prophylactic treatments at their final destination. At the time of writing, August 2017, two cuttings have survived - an uninfected T. harmandii now over $33 \mathrm{~cm}$ and showing signs of vigorous growth (Fig. 5, foreground), and another uninfected $T$. cf. magnum, which was grafted onto an established Malaysian T. rafflesiae Planch. This scion has kept its original leaf and has begun to grow; a terminal bud is producing a leaf and its shoot is about $2 \mathrm{~cm}$ long (Fig. 6). Grafting, even to a different species of Tetrastigma, appears to offer another option to propagation from softwood cuttings.

\section{Rafflesia lagascae host cuttings (RLT)}

Upon arriving at USBG, the first set of RLT cuttings collected in July 2015 were placed on long-fibre sphagnum moss and drenched with fungicide and insecticide. The second batch of RLT cuttings collected in August 2016 were placed in commercial potting mix (Fig. 7) and treated with 500 ppm GA3 twice. Both batches of cuttings, even after several months, unlike RST cuttings, failed to root and ultimately expired. On the other hand, the two infected cuttings collected in May 2017 were immediately treated with rooting hormone upon arriving at USBG. The piece with the largest diameter $(1 \mathrm{~cm})$ survived long enough to be employed in a grafting experiment whereby an intact root system of $T$. rafflesiae was attached at the distal end, and the top of the infected stem was side grafted with three vegetative stems of T. rafflesiae (Fig. 8). The grafted specimen survived for 33 days. The longevity of this specimen showed great promise until the attached root system failed and bacterial soft rot invaded the bottom of the stem piece. The other piece was not grafted and developed soft rot, eventually expiring within three weeks. The third RLT infected piece, hand-carried along with the RST cuttings, expired within one week of arrival. It endured severe stress during the remainder of the fieldwork for ten days, often at high ambient temperatures. Shipping by airmail introduces unknown variables; however, if it results in shorter transit time, it is preferable to additional time spent at uncontrolled temperatures. It is probably not coincidental that the segment with the largest diameter and shorter transit time was the most resilient. These factors should be considered in future collecting efforts.

\section{LESSONS LEARNED}

These initial attempts at cultivating Rafflesia in the US have been unsuccessful; however, they represent the first time live Rafflesia has been imported into the US and survived there for a period of time. In future collections we plan to pre-treat cuttings with antimi- 
Fig. 7 Rafflesia lagascae-infected Tetrastigma (RLT) cuttings at USBG, collected in August 2016. Upon arrival at USBG, they were laid on commercial potting mix. Photo: USBG.

Fig. 8 Rafflesia lagascae-infected Tetrastigma cutting grafted onto T. rafflesiae. An intact root system of $T$. rafflesiae was attached at the distal end, and the top of the infected stem was side-grafted with three vegetative stems of $T$. rafflesiae. The grafted specimen survived for 33 days before bacterial soft rot invaded the bottom of the grafted piece. Photo: USBG.
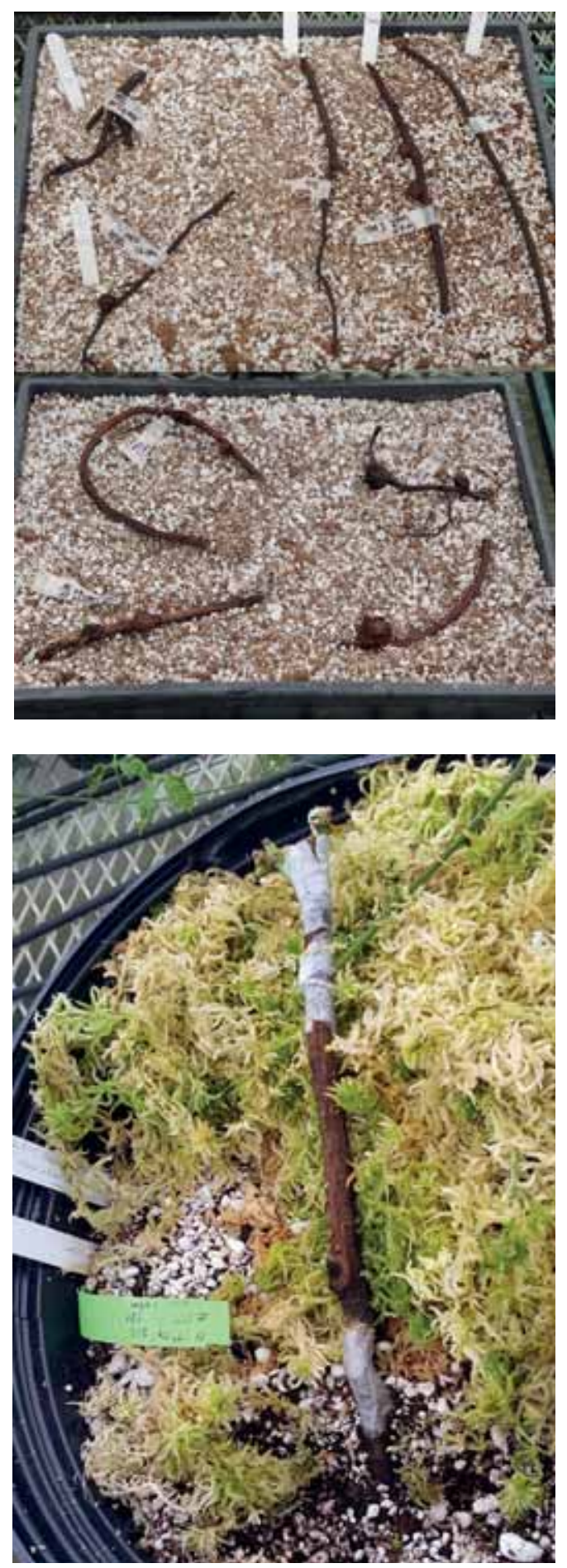
crobials immediately after collection. The most challenging factor is ensuring that cuttings are kept in moderate environmental conditions while permits are processed, which, at a minimum, can only be obtained within 48 hours after collection. Though our efforts have not yielded direct success in propagating Rafflesia, we now have the building blocks for future success. With host species $T$. harmandii and $T$. cf. magnum in cultivation, we can begin using these specimens for future experimentation involving grafting of infected material and seed inoculation trials.

\section{RESULTS OF SEED VIABILITY TESTING AND IN VITRO GERMINATION} ASSAYS

Rafflesia speciosa (RS) seeds were collected from two mature fruits in August 2016 (Fig. 9). These seeds were subjected to in vitro germination assays in January 2017 as described above and in the Appendix. The tetrazolium test showed that non-heat killed WF seeds and RS seeds were viable, staining red as expected (Fig. 10). This seed lot was tested in vitro for germination using various plant growth regulators (PGR) in three relative concentrations (low, medium, high). Germination was only observed in WF seeds in medium concentrations of GA4+7, KAR1, kinetin and BRA within one week. However, no germination was observed in RS seeds (Fig. 11) in both conditioned and non-conditioned treatments. The four PGRs that stimulated germination in WF seeds were combined and applied on RS seeds, but this still did not induce germination (Fig. 12).

In holoparasitic Orobanchaceae, the synthetic strigolactone GR24 has been used to trigger germination in the absence of an actual host (Pouvreau et al., 2013). In vitro germination of Rafflesia patma Blume seeds in GR24 mixed with host extracts was also attempted by Wicaksono et al. (2016) with negative results. Other plant growth regulators such as 6-benzylaminopurine (BA), 1-napthlaeneacetic acid (NAA), 2,4-dichlorophenoxyacetic acid (2,4-D) and kinetin in different combinations were also used but again with no success (Sukamto \& Mujiono, 2010). These standard PGRs have failed to induce germination in Rafflesia possibly because the seeds require some other unknown host-derived substances. Rafflesia spp. seem to be host-specific (Pelser et al., 2016). Tetrastigma loheri is the preferred host species of $R$. lagascae, but even if $T$. loheri is sympatric with $R$. speciosa, $R$. speciosa does not parasitise $T$. loheri, and infects T. harmandi and T. cf. magnum (Pelser et al., 2016) instead. Conditioning for prolonged periods of time ( $>1$ month) may also be required by RS seeds to germinate. Holoparasitic Striga and Orobanche have been known to require conditioning for six months (Logan \& Stewart, 1992). Rafflesia buds have also been observed to emerge from the host at least two years after artificial inoculation (Marius Gabin, pers. comm.). Other biotic factors may also be required for germination, such as mycorrhizal species (Mursidawati et al., 2015). Additionally, propagation efforts should be mindful that embryos may actually be absent from the seeds since Rafflesia is known to form agamospermous seeds (Nais, 2001). 
Fig. 9 Rafflesia speciosa.

(a) Dehiscent fruit showing minute seeds, with GPS coordinates of location and elevation. (b) Palm-size mature fruit that has not yet dehisced. (c) Section of fruit excised from (b).

Photo: Jeanmaire Molina.

Fig. 10 Tetrazolium (TZ) test. Wildflower (WF) seeds (top) and Rafflesia speciosa (RS) seeds (bottom), about $1 \mathrm{~mm}$ (inset shows RS seeds under 100x magnification). Reddish colour change indicates seeds are viable vs dark-brown colour of heat-killed seeds. Photo: Jeanmaire Molina.
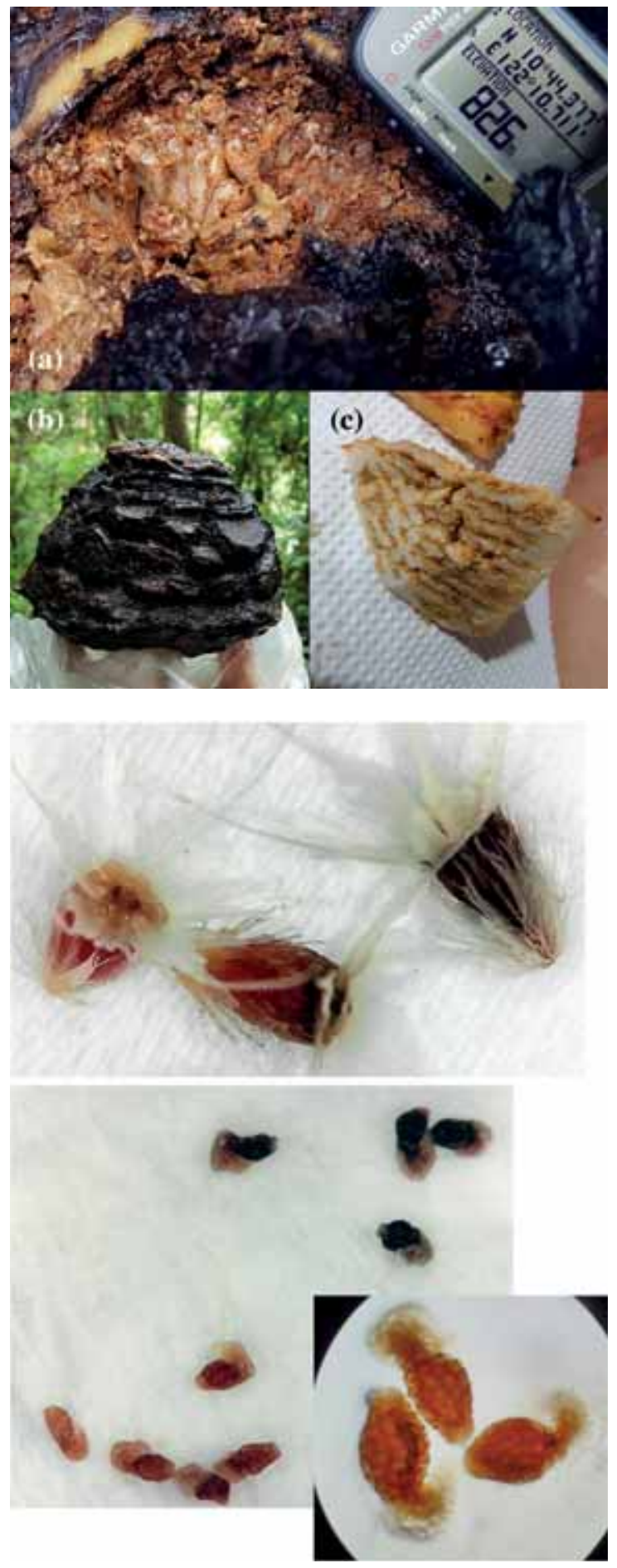

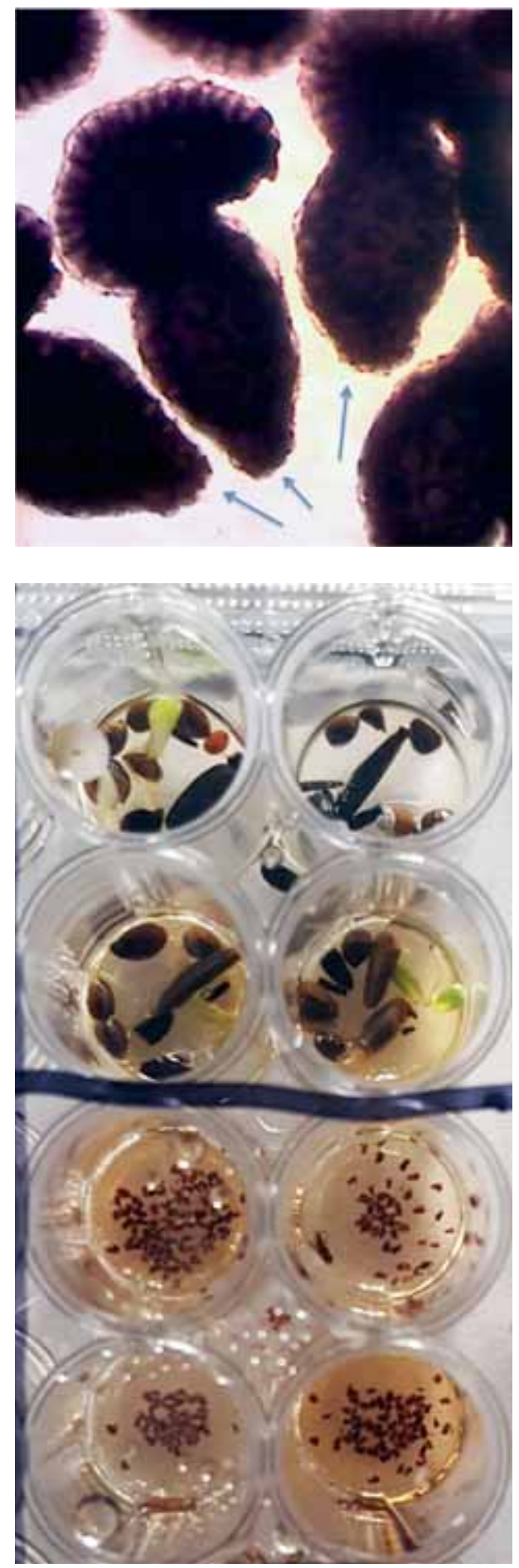

Fig. 11 RS seeds, about $1 \mathrm{~mm}$ long. No germination observed in all treatments using eight PGRs even after six weeks. Arrows indicate where radicle growth is expected. Photo taken with MD200, 2-megapixel camera included in AmScope stereomicroscope. Photo: Jeanmaire Molina.
Fig. 12 Four-PGR (GA4+7, KAR1, kinetin, BRA) treatment of WF and RS seeds. Germination was observed in three (of four, top quadrant) replicates of WF seeds receiving medium concentrations of the four PGRs. No germination was observed in RS seeds (bottom quadrant). Photo: Jeanmaire Molina. 


\section{VIVIAN RAFFLESIA GARDEN}

In July 2016, Jeanmaire Molina and Ronniel Pedales visited the Rafflesia garden at Ranau, Poring Springs (Sabah, Malaysia) owned by Viviane and her father, Marius Gabin. Their garden is home to Rafflesia keithii Meijer (Fig. 13), which produces blooms ranging from 70 to $88 \mathrm{~cm}$ in diameter, the largest flowers in Sabah. R. keithii preferentially parasitises Tetrastigma leucostaphylum (Dennst.) Alston. In 2004, Mr Gabin artificially inoculated the mature host vine with $R$. keithii seeds and, in 2007, a Rafflesia flower bloomed close to the site of inoculation. In their garden, there are about 20 host vines, and Mr Gabin believes that about 80 per cent of the Rafflesia infections were from his own inoculations, which he performs once a year on one Tetrastigma vine. Squirrels and ants have been observed to naturally disperse Rafflesia seeds. The garden yields about seven blooms a year, earning about RM2500 (around £450) from curious tourists. This suggests that cultivation of these plants can be a viable source of supplementary income that could motivate locals to conserve the rare plant. Mr Gabin is assured a consistent supply of Rafflesia seeds for artificial inoculation because two or three Rafflesia fruits mature each year. He believes the seeds are viable for up to six months.

Mr Gabin has demonstrated to the authors how he inoculates the vine and selects $1 \mathrm{~cm}$ wide roots. A shallow incision is made in the bark using a clean knife, enough to reach phloem tissue, and about five seeds are deposited in the incision which is gently pinched to seal it (Fig. 14). If successful, buds are seen two to seven years after inoculation. It takes about nine to twelve months to bloom, and another eight months for fruits to mature. Buds are shaded from direct sunlight with a tarpaulin. Wicaksono et al. (2016) reported placing Rafflesia patma seeds in Tetrastigma leucostaphylum host stem with no germination seen even after 628 days. However, spreading the seeds, instead of depositing them within an incision, has been reported to be successful (Wicaksono et al., 2016).

Mr Gabin has also tried grafting an infected host vine, but this was not successful, and has been most successful with his inoculation technique, which he openly shares with others to benefit Rafflesia conservation efforts. In May 2017, Jeanmaire Molina demonstrated the inoculation technique to locals in Miag-ao, Iloilo, in order to promote the prospect of sustainable ecotourism, while conserving Rafflesia and its habitat. The Philippine government recognises the uniqueness and value of these species, encourages research and develops partnerships with the academe to better understand its biology and propagation, and to provide opportunities in the future for reintroduction or restocking of the species in areas where the natural populations have already been depleted.

It is unfortunate that most Filipinos are unaware of the plant, since the Philippines is the centre of Rafflesia diversity. In the Philippines, only one ( $R$. magnifica=R. mira) of thirteen spp. is currently listed as critically endangered (Madulid et al., 2008) because population and distribution studies are lacking for each species, in spite of many being single-island endemics. $R$. schadenbergiana Göpp. ex Hieron. in Mindanao, Philippines, had previously been thought to be extinct until 1994 when it was rediscovered and is known to occur on only two Tetrastigma individuals (Barcelona et al., 2008). And so, 

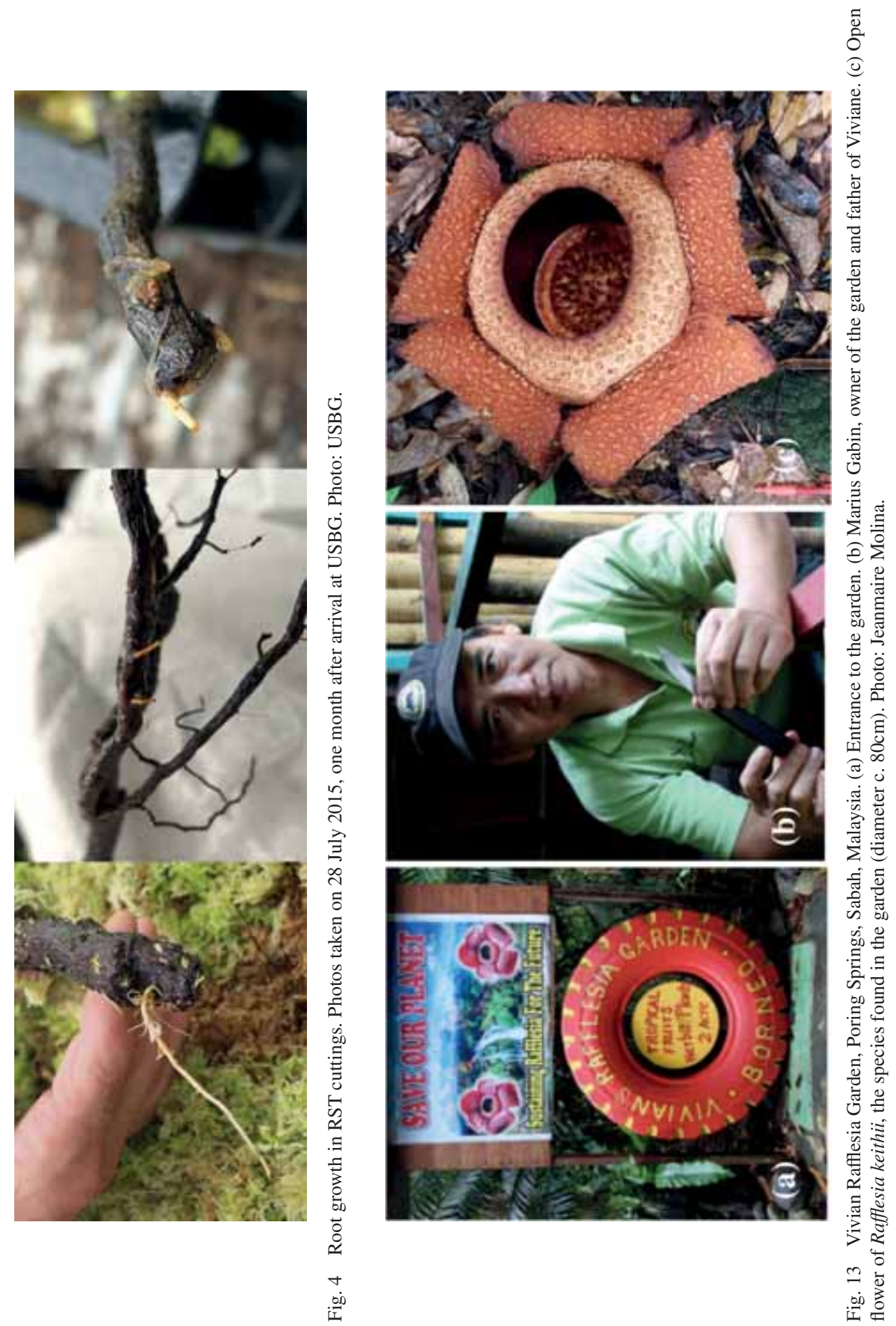


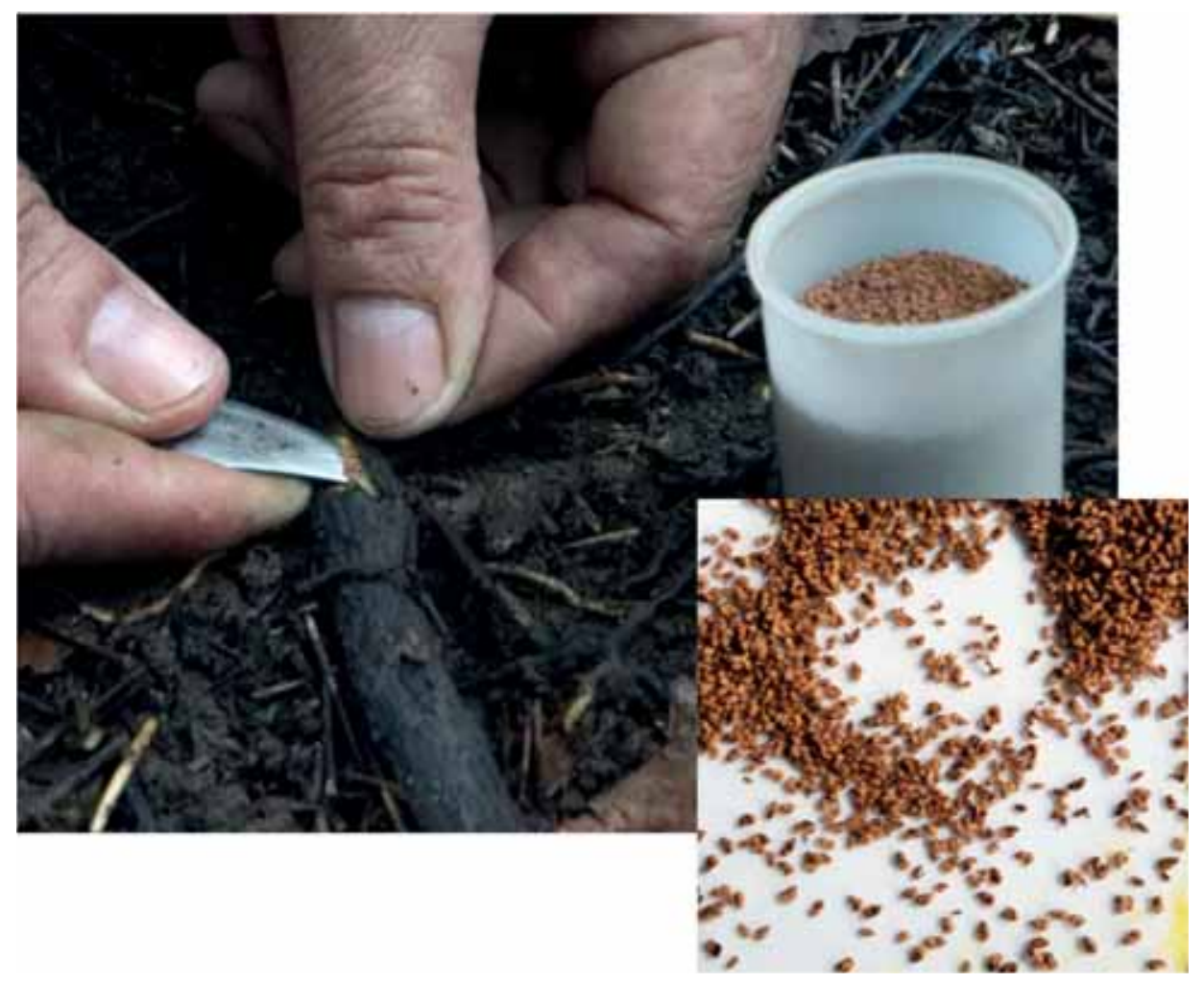

Fig. 14 Inoculation of Tetrastigma vine with Rafflesia keithii seeds. Marius Gabin makes an incision on the vine and deposits five or six Rafflesia seeds inside. Inset: Rafflesia keithii seeds, $1 \mathrm{~mm}$ long. Photo: Jeanmaire Molina.

more than ever, ex situ propagation studies as well as advancement of in situ efforts coupled with public outreach campaigns are needed to conserve these magnificent Rafflesia species for future generations.

\section{CONCLUSION}

Though our attempts to propagate Rafflesia-infected Tetrastigma cuttings and germinate Rafflesia seeds in vitro have not yet succeeded, we hope that our results will guide future efforts. Permitting work in the Philippines requires coordination among national, regional and local authorities, and requires great diligence for success. Keeping highly perishable propagules in good condition during the course of several days of journeying was a significant challenge; reducing transit time under such conditions is critical. The arrival of live Rafflesia in the US also marks a first for American horticulture, and surmounting the many logistical issues involved in the collecting, permitting, shipping and importing of a species parasitic on an economically important family (Vitaceae) made this effort particularly challenging. However, our research team continues to learn 
and believes success in ex situ conservation of Rafflesia beyond the continent of origin is within reach. We now have two Philippine Rafflesia host species at USBG, which we can use for future experimentation involving grafting of infected material and seed inoculation trials. Perhaps the most significant lesson of our efforts is the recognition that successful ex situ conservation of this type is wholly dependent on establishing robust collaborations between botanical conservation institutions and local experts. This is required to build the trust necessary to obtain permits to collect and export plants. But, more critically, close collaboration with the professionals in the field working with target plant species is the only way to make sure that conservation programmes are leveraging all available technical knowledge. In this example, our research team was particularly excited to learn of Mr Gabin's success in artificially inoculating Rafflesia seeds into its host. His open knowledge sharing presents new propagation strategies for our research team, greatly improving the prospect of successful ex situ conservation of this botanical treasure.

\section{ACKNOWLEDGEMENTS}

We express sincere gratitude to Marius Gabin for sharing his horticultural experience in Rafflesia propagation, to his wife, who was very accommodating, and to Mona who helped us navigate Sabah. We thank Dr Jun Wen of the Smithsonian Institute for providing additional species of Tetrastigma for future propagation efforts. We also thank Eric Leavitt and Jaclyn de Leon at USBG for expert horticultural care and botanical record keeping. We are most grateful to our collaborators in the Philippines, to our field guides and assistants, to the municipal mayors (Mayors Macario Napulan, Nelson de Leon, Edgar Ramores) and their staff, as well as local government personnel who have been very supportive of our endeavours. We thank Julie Barcelona, Marites Muyong, Raymond Nugara, Ani Malate, Rico Brizo, Nermalie Lita, Josefina de Leon, Anson Tagtag, Giselle of WRPSNCR, Jane Branton, Mark Montealto, Isidro Mosura, Nato Andraje, Hector Garrido, Lea Gella Blancaflor, Llane Orale, Edgardo Ferrer, Marizon Vega, Ian Fontanilla, Lourdes Wagan, Jim Sampulna, Noel Empleo, Joseph Morin, Godfrey deShields, David Nelson, David Cohen, Cathy Seringer, Jeff Kane, Ana Labrador, Tito Evangelista, Michael Purugganan, Jun Mangalindan, Michael Ng and all who have contributed one way or another. Jeanmaire Molina's Indiegogo funders have seeded this project, and their faith and optimism have been most encouraging. Jeanmaire Molina has made it her life's mission to conserve Philippine Rafflesia, in memory of eminent Filipino botanist, Leonard Co.

\section{REFERENCES}

BALETE, D., PELSER, P., NICKRENT, D. \& BARCELONA, J. (2010). Rafflesia verrucosa (Rafflesiaceae), a new species of small-flowered Rafflesia from eastern Mindanao, Philippines. Phytotaxa, 10, 49-57. 
BARBROOK, A.C., HOWE, C.J. \& PURTON, S. (2006). Why are plastid genomes retained in non-photosynthetic organisms? Trends in Plant Science, 11(2), 101-108.

BARCELONA, J.F., PELSER, P.B., BALETE, D.S. \& CO, L.L. (2009). Taxonomy, ecology, and conservation status of Philippine Rafflesia (Rafflesiaceae). Blumea, 54(1-3), 77-93.

BARCELONA, J.F., PELSER, P.B., TAGTAG, A.M., DAHONOG, R.G. \& LILANGAN, A.P. (2008). The rediscovery of Rafflesia schadenbergiana Göpp. ex Hieron. (Rafflesiaceae). Flora Malesiana Bulletin, 14(3), 162-165.

CORBINEAU, F., XIA, Q., BAILLY, C. \& EL-MAAROUF-BOUTEAU, H. (2007). Ethylene, a key factor in the regulation of seed dormancy. Frontiers in Plant Science, 5(539), n.p.

DAVIS, C.C., LATVIS, M., NICKRENT, D.L., WURDACK, K.J. \& BAUM, D.A. (2007). Floral gigantism in Rafflesiaceae. Science, 315(5820), 1812.

FINKELSTEIN, R.R. (2010). The role of hormones during seed development and germination. In: DAVIES, P.J. (ed.), Plant Hormones Biosynthesis, Signal Transduction, Action! Kluwer Academic Publishers, Dordrecht, pp. 549-573.

FLEMATTI, G.R., DIXON, K.W. \& SMITH, S.M. (2015). What are karrikins and how were they 'discovered' by plants? BMC Biology, 13(1), 108.

KĘPCZYŃSKI, J. \& BIAŁECKA, B. (1994). Stimulatory effect of ethephon, ACC, gibberellin $\mathrm{A}(3)$ and $\mathrm{A}(4+7)$ on germination of methyl jasmonate inhibited Amaranthus caudatus L. seeds. Plant Growth Regulation, 14(3), 211-216.

KROSHEL, J. (2001). A Technical Manual for Parasitic Weed Research and Extension. Kluwer Academic Publishers, Dordrecht.

LI, W., KHAN, M.A., YAMAGUCHI, S. \& KAMIYA, Y. (2005). Effects of heavy metals on seed germination and early seedling growth of Arabidopsis thaliana. Plant Growth Regulation, $46(1), 45-50$.

LOGAN, D.C. \& STEWART, G.R. (1992). Germination of the seeds of parasitic angiosperms. Seed Science Research, 2(4), 179-190.

MADULID, D.A., TANDANG, D.N. \& AGOO, E.M.G. (2008). Rafflesia magnifica. The IUCN Red List of Threatened Species 2008. Available online: http://dx.doi.org/10.2305/IUCN. UK.2008.RLTS.T133709A3873727.en (accessed April 2017).

MEIJER, W. (1997). Rafflesiaceae. Flora Malesiana-Series 1, Spermatophyta, 13(1), 1-42.

MIRANSARI, M. \& SMITH, D.L. (2014). Plant hormones and seed germination. Environmental and Experimental Botany, 99, 110-121.

MOLINA, J., HAZZOURI, K.M., NICKRENT, D., GEISLER, M., MEYER, R.S., PENTONY, M.M., FLOWERS, J.M., PELSER, P., BARCELONA, J., INOVEJAS, S.A., UY, I., YUAN, W., WILKINS, O., MICHEL, C., LOCKLEAR, S., CONCEPCION, G.P. \& PURUGGANAN, M.D. (2014). Possible loss of the chloroplast genome in the parasitic flowering plant Rafflesia lagascae (Rafflesiaceae). Molecular Biology and Evolution, 31(4), 793-803.

MURSIDAWATI, S., NGATARI, N., IRAWATI, I., CARDINAL, S. \& KUSUMAWATI, R. (2015). Ex situ conservation of Rafflesia patma Blume (Rafflesiaceae) - an endangered emblematic parasitic species from Indonesia. Sibbaldia, 13, 99-110.

NAIS, J. (2001). Rafflesia of the World. Sabah Parks, Borneo, Malaysia. 
NAIS, J., REPIN, R. \& MIADIN, R. (2015). Rafflesia conservation research in Sabah, Malaysia. In: Proceedings of International Symposium on Indonesian Giant Flowers Rafflesia and Amorphophallus, Bengkulu, Indonesia, 14-17 September 2015.

NG, M. (2012). Blooming Rafflesia, biggest flower in the world! Available online: www. mysabah.com/wordpress/blooming-rafflesia (accessed 24 March 2016).

NIKOLOV, L.A., TOMLINSON, P.B., MANICKAM, S., ENDRESS, P.K., KRAMER, E.M. \& DAVIS, C.C. (2014). Holoparasitic Rafflesiaceae possess the most reduced endophytes and yet give rise to the world's largest flowers. Annals of Botany, 114(2), 233-242.

PELSER, P.B., NICKRENT, D.L. \& BARCELONA, J.F. (2016). Untangling a vine and its parasite: Host specificity of Philippine Rafflesia (Rafflesiaceae). Taxon, 65(4), 739-758.

PELSER, P.B., NICKRENT, D.L., CALLADO, J.R.C. \& BARCELONA, J.F. (2013). Mt. Banahaw reveals: The resurrection and neotypification of the name Rafflesia lagascae (Rafflesiaceae) and clues to the dispersal of Rafflesia seeds. Phytotaxa, 131(1), 35-40.

PELSER, P.B., NICKRENT, D.L., GEMMILL, C.E.C. \& BARCELONA, J.F. (in press). Genetic diversity and structure in the Philippine Rafflesia lagascae complex inform its taxonomic delimitation and conservation. Systematic Botany.

POUVREAU, J.B., GAUDIN, Z., AUGER, B., LECHAT, M.M., GAUTHIER, M., DELAVAULT, P. \& SIMIER, P. (2013). A high-throughput seed germination assay for root parasitic plants. Plant Methods, 9(1), 32.

SARATH, G., BETHKE, P.C., JONES, R., BAIRD, L.M., HOU, G. \& MITCHELL, R.B. (2006). Nitric oxide accelerates seed germination in warm-season grasses. Planta, 223(6), 11541164.

SAWAN, Z.M., MOHAMED, A.A., SAKR, R.A. \& TARRAD, A.M. (2000). Effect of kinetin concentration and methods of application on seed germination, yield components, yield and fiber properties of the Egyptian cotton (Gossypium barbadense). Environmental and Experimental Botany, 44(1), 59-68.

STEBER, C.M. \& MCCOURT, P. (2001). A role for brassinosteroids in germination in Arabidopsis. Plant Physiology, 125(2), 763-769.

SUKAMTO, L.A. \& MUJIONO, M. (2010). In vitro culture of holoparasite Rafflesia arnoldii R. Brown. Buletin Kebun Raya: The Botanic Garden Bulletin, 13(2), 79-85.

VERMA, P. \& MAJEE, M. (2013). Seed germination and viability test in Tetrazolium (TZ) Assay. Bio-protocol, 3(17), 1-4.

WICAKSONO, A., MURSIDAWATI, S., SUKAMTO, L.A. \& DA SILVA, J.A.T. (2016). Rafflesia spp.: propagation and conservation. Planta, 244(2), 289-296.

YONEYAMA, K., AWAD, A.A., XIE, X., YONEYAMA, K. \& TAKEUCHI, Y. (2010).

Strigolactones as germination stimulants for root parasitic plants. Plant and Cell Physiology, 51(7), 1095-1103.

\section{APPENDIX}

Format of the non-conditioned 48-well plate used in in vitro germination assays of Rafflesia speciosa (RS) and wildflower seeds (WF). Various plant growth regulators 
were tested in three relative concentrations: low, medium and high, with medium as standard concentration from literature known to stimulate germination. These include gibberellins (GA3, GA4+7), kinetin/cytokinin (Sigma Aldrich cat. K3253), ethylene/ ethephon (Sigma Aldrich cat. C0143), sodium nitroprusside (SNP, source of nitric oxide, Sigma Aldrich cat. PHR1423-1G) (Kępczyński \& Białecka, 1994; Sawan et al., 2000; Li et al., 2005; Sarath et al., 2006; Finkelstein, 2010; Corbineau et al., 2014; Miransari \& Smith, 2014), brassinolides (BRA, from Power Grown; Steber \& McCourt, 2001), karrikin (KAR1, from Olchemim, Czech Republic; Flematti et al., 2015; David Nelson, University of Georgia, pers. comm.) as well as a known germination stimulant in holoparasite Orobanchaceae: synthetic strigolactone, GR24 (from Olchemim, Czech Republic; Yoneyama et al., 2010; Pouvreau et al., 2013). Dilutions of PGRs were made with 50\% 1M HEPES buffer and 0.2-0.5\% PPM (Plant Preservative Mixture, a heatstable broad spectrum biocide, from Plant Cell Technology, Washington, DC).

\begin{tabular}{|l|l|l|l|l|l|l|l|l|}
\hline $\begin{array}{l}W F \\
\text { low }\end{array}$ & GA3 & GA4+7 & KAR1 & GR24 & kinetin & ethylene & SNP & BRA \\
\hline $\begin{array}{l}R S \\
\text { low }\end{array}$ & GA3 & GA4+7 & KAR1 & GR24 & kinetin & ethylene & SNP & BRA \\
\hline $\begin{array}{l}\text { WF } \\
\text { medium }\end{array}$ & GA3 & GA4+7 & KAR1 & GR24 & kinetin & ethylene & SNP & BRA \\
\hline $\begin{array}{l}\text { RS } \\
\text { medium }\end{array}$ & GA3 & GA4+7 & KAR1 & GR24 & kinetin & ethylene & SNP & BRA \\
\hline $\begin{array}{l}\text { WF } \\
\text { high }\end{array}$ & GA3 & GA4+7 & KAR1 & GR24 & kinetin & ethylene & SNP & BRA \\
\hline $\begin{array}{l}\text { RS } \\
\text { high }\end{array}$ & GA3 & GA4+7 & KAR1 & GR24 & kinetin & ethylene & SNP & BRA \\
\hline
\end{tabular}

